\title{
Precoded food records compared with weighed food records for measuring dietary habits in a population of Swedish adults
}

\author{
By Wulf Becker, Maria Lennernäs, Inga-Britt Gustafsson, Jóhanna Haraldsdóttir, \\ Margaretha Nydahl, Bengt Vessby and Anne Ytterfors \\ Received: July 28, 1998; Accepted: November 23, 1998
}

\begin{abstract}
In a cross-over design, 82 women and men recorded their food intake by a precoded 7-day record book (PR) including both standard portions in household measures and photographs, and a weighed 7-day record (WR), respectively. Single 24-h urine samples, for determination of nitrogen excretion, were collected for 39 subjects during the WR period.

Comparing the PR to the WR method, the mean intake of some foods, as cheese, was higher, and bread and vegetables lower. For energy and nutrients, the fat energy percent (E\%) was higher, and protein $\mathrm{E} \%$, dietary fibre, iron, thiamin, folate, carotene and $\alpha$-tocopherol were all lower. Protein intake registered by the PR method was $20 \%$ lower compared to 24 -h urine samples, and $11 \%$ lower for the WR method. The results indicate that some of the standard portion sizes, used by the PR method, contributed to the observed differences in food and nutrient intakes. The subjects found it easier and less time-consuming to record their food intake with the PR than with the WR method. The time spent on processing data was reduced by $50 \%$ when using the PR method.The results of the study will be used for improvements in the design of the PR for use in large-scale dietary surveys for monitoring dietary habits.
\end{abstract}

\section{Introduction}

A major obstacle to using food records in large population surveys is the large, costly workload linked with coding (e.g. allocating codes and weights to foods) and entering the data into the computer. Use of precoded food record forms could substantially reduce these costs and also simplify the work for the person recording his or her food intake, eliminating or reducing the need for weighing and writing. In 1989, a combined nation-wide household budget and dietary survey was carried out by Statistics Sweden in cooperation with the National Food Adminstration (1). The survey was originally designed to measure household acquisition of food (both expenditures and amounts), but in order to obtain data on individual dietary intake a precoded 7-day record book (PR) was developed and included in the survey $(2,3)$. The record book was designed in such a way that it would give relatively detailed information about an individual's food intake but still be easy to fill in by the participant. This requirement was important since the survey was cumbersome for the household. The PR contains preprinted alternatives of ca. 100 commonly eaten foods and amounts are to be estimated in standard household measures, pieces, glasses, etc. and with the help of photographs.

In order to evaluate the PR, the food intake of 82 adults was measured with this method and with a weighed 7-day record (WR), the latter in combination with 24-h urinary collection. A sub-group also participated in a study in which the time savings in coding and entering of data were quantified and the participants' views on using the PR were investigated.

\section{Subjects and methods}

Subjects: Dietary data were collected from 44 males and 38 females with a mean age of 40 years (range 21-63) and 40 years (range 22-61), respectively. The subjects had been randomly sampled from 20-60 year old persons, mainly consisting of employees of the Swedish Telephone company in Uppsala. Most of these had participated in an intervention study carried out in 1990, in which food intake had been measured using the PR (4). Altogether 141 persons were asked to participate, with a final participation rate of $58 \%$. The subjects were randomised either to start with the WR or with the PR. The subjects were weighed before, in between and after each dietary period. The initial mean weights for men were $79.1 \mathrm{~kg}$ (range 61.9-135) and for women $65.3 \mathrm{~kg}$ (range 43.2-93.8), which did not change significantly during the record periods. The WR and PR were kept during seven consecutive days, respectively, with a break in between of typically 1-2 weeks for most of the participants (mean 9 days, range 1-58). The data were collected during 1993 and 1994.

The precoded record book $(P R)$ : The $\mathrm{PR}$ gives pre-printed alternatives for foods and dishes commonly eaten at main meals (breakfast, lunch, dinner). Time of day and place where the meals were eaten ( 7 preprinted alternatives) was indicated for each meal. Photographs were used to show the portion sizes (four alternatives, each on one plate) as a guide to estimate the portions of the meal components (meat/ fish; potatoes/pasta/rice; vegetables/salad. The use of spreads on sandwiches was also estimated by photographs showing four alternatives. For other pre-printed foods the respondent indicated the amount consumed in household measures (pieces, glasses, cups, spoons, deciliters, etc.) and predefined standard portions were allocated in the data analyses. These portions were mainly derived from Swedish reference publications such as Vikttabeller (Food Weight Tables) (5). In addition, it was also possible to record, in free text, other types of foods eaten at these meals. Snacks and other in-between meals were

Wulf Becker ${ }^{1}$, Dr Med Sc, Maria Lennernäs ${ }^{2}$, Dr Med Sc, Inga-Britt Gustafsson ${ }^{3}, \mathrm{PhD}$ professor, Jóhanna Haraldsdóttir ${ }^{4}$, $\mathrm{PhD}$ associate professor, Margaretha Nydahl ${ }^{5}$, Dr Med Sc, Bengt Vessby ${ }^{6}$ MD professor, Anne Ytterfors ${ }^{6}$ Dietitian.

${ }^{1}$ National Food Administration, Uppsala, Sweden, ${ }^{2}$ Dept of Medical Sciences, Nutrition Unit Uppsala University, ${ }^{3}$ Dept of Culinary Art, University of Örebro, ${ }^{4}$ Research Department of Human Nutrition, Royal Veterinary and Agricultural University, Copenhagen, Denmark, ${ }^{5}$ Dept of Domestic Sciences, Uppsala University, ${ }^{6}$ Unit for Clinical Nutrition Research, Dept of Public Health and Caring Sciences, Uppsala University

Correspondance. Wulf Becker, National Food Administration, P.O. Box 622, SE-751 26 Uppsala Sweden.E-mail: wube@slv.se 
Table 1. Average consumed amounts, mean and (SD), of some foods among adults $(\mathrm{n}=82)$ according to the precoded record book (PR) and the weighed record (WR), Spearman correlation coefficients and Kappa values $\left(\kappa_{w}\right)$.

\begin{tabular}{lrrrrr}
\hline Food group & \multicolumn{1}{c}{$\mathrm{PR}$} & $\mathrm{WR}$ & $\mathrm{p}$ & $\mathrm{\kappa}_{\mathrm{w}}$ & $\mathrm{r}$ \\
\hline Spreads & $26(15)$ & $26(15)$ & & 0.28 & $0.47 * * *$ \\
Cheese & $39(31)$ & $32(22)$ & $*$ & 0.51 & $0.69 * * *$ \\
Milk & $278(197)$ & $248(175)$ & & 0.47 & $0.73 * * *$ \\
Potatoes & $138(59)$ & $129(61)$ & & 0.24 & $0.37 * * *$ \\
Vegetables & $84(63)$ & $109(90)$ & $* *$ & 0.28 & $0.47 * * *$ \\
Roots & $9(15)$ & $17(25)$ & $* *$ & 0.23 & $0.40 * * *$ \\
Fruit & $114(80)$ & $115(76)$ & & 0.50 & $0.70 * * *$ \\
Juice & $63(92)$ & $51(89)$ & & 0.44 & $0.55 * * *$ \\
Bread & $89(35)$ & $104(41)$ & $* *$ & 0.57 & $0.74 * * *$ \\
Buns, cakes & $51(34)$ & $53(33)$ & & 0.38 & $0.54 * * *$ \\
Porridge, gruel & $40(76)$ & $29(63)$ & & 0.58 & $0.62 * * *$ \\
Pasta & $28(31)$ & $40(41)$ & & 0.23 & $0.38 * * *$ \\
Cereals, müsli & $5(9)$ & $11(16)$ & $* * *$ & 0.61 & $0.73 * * *$ \\
Meat, poultry & $87(41)$ & $96(43)$ & & 0.31 & $0.49 * * *$ \\
Sausages & $30(26)$ & $33(29)$ & & 0.19 & $0.35 * *$ \\
Fish & $35(28)$ & $36(33)$ & & 0.23 & $0.35 * *$ \\
Soft drinks & $102(133)$ & $102(130)$ & & 0.41 & $0.59 * * *$ \\
Alcoholic drinks & $226(182)$ & $193(196)$ & $* *$ & 0.41 & $0.63 * * *$ \\
Coffee, tea & $951(385)$ & $868(410)$ & & 0.49 & $0.68 * * *$ \\
& & & & \\
\end{tabular}

The superscripts refer to level of significance, i.e. for difference in food intake and Spearman coefficients: $* \mathrm{p}<0.05 ; * * \mathrm{p}<0.01 ; * * * \mathrm{p}<0.001$ recorded, in free text, on a separate page for each day, and the amounts given in household measures as in an open-ended food record.

The participant visited the dietitian, who gave an introductory description of the PR to the subject. After a week the participant returned the completed book. Food that was not precoded in the PR was then coded according to the National Food Administration's food composition database (6) before the data were entered. A
Table 2. Intake frequencies and average amounts consumed per eating occasion among adults $(n=82)$ according to the precoded record book $(P R)$ and weighed record (WR).

\begin{tabular}{|c|c|c|c|c|c|c|}
\hline \multirow[b]{2}{*}{ Food group } & \multicolumn{3}{|c|}{ Frequency/day } & \multicolumn{3}{|c|}{ Average portion $(\mathrm{g})$} \\
\hline & PR & WR & $\mathrm{p}$ & PR & WR & $\mathrm{p}$ \\
\hline Spreads & 1.79 & 2.02 & $* *$ & 15 & 14 & \\
\hline Cheese & 1.22 & 1.28 & & 32 & 26 & $* * *$ \\
\hline Milk & 1.14 & 1.36 & $* *$ & 245 & 196 & $* * *$ \\
\hline Potatoes & 0.75 & 0.74 & & 187 & 174 & $*$ \\
\hline Vegetables & 1.73 & 1.95 & $*$ & 49 & 60 & $*$ \\
\hline Roots & 0.19 & 0.25 & & 50 & 74 & \\
\hline Fruit & 1.23 & 1.13 & & 97 & 112 & $* * *$ \\
\hline Juice & 0.28 & 0.28 & & 231 & 174 & $* * *$ \\
\hline Bread & 2.37 & 2.39 & & 39 & 46 & $* * *$ \\
\hline Cereals, müsli & 0.24 & 0.27 & & 21 & 45 & $* * *$ \\
\hline Pasta & 0.19 & 0.20 & & 150 & 207 & $* *$ \\
\hline Porridge, gruel & 0.17 & 0.13 & & 246 & 216 & $* *$ \\
\hline Buns, cakes & 1.20 & 1.38 & $*$ & 49 & 40 & $* *$ \\
\hline Meat, poultry & 1.03 & 0.98 & & 86 & 104 & $* * *$ \\
\hline Sausages & 0.41 & 0.44 & & 80 & 87 & \\
\hline Fish & 0.48 & 0.50 & & 79 & 83 & \\
\hline Soft drinks & 0.37 & 0.41 & & 280 & 248 & \\
\hline Alcoholic drinks & 0.78 & 0.74 & & 298 & 273 & \\
\hline Coffee, tea & 4.36 & 4.58 & & 225 & 191 & $* * *$ \\
\hline
\end{tabular}

Values significantly different from weighed record:

$* \mathrm{p}<0.05 ; * * \mathrm{p}<0.01 ; * * * \mathrm{p}<0.001$ special computer program was developed for direct conversion of the precoded alternatives into amounts and food codes. The intake of food and nutrients was calculated using a commercial software program, MATs (7), and the food composition data from the National Food Administration (6). Individual food items are grouped into 35 main food groups.

Weighed food records (WR): The subjects also kept a weighed food record. At their first visit to the dietitian the subjects were instructed on how to use the scale (Soehnle, precision $1 \mathrm{~g}$ ). Most of the participants were of working age, some of them had to eat at restaurants and then could not always weigh their food. For estimating the food intake at such meals, the participants were given a set of photographs and drawings showing portion sizes of food components in main meals, amount of spread used on sandwiches, portion sizes of fruits, bread, etc. However, they were instructed not to use estimations if they were able to use the scale. They kept the food records for seven consecutive days. The use of the scale or photographs/drawings for recording weights was evaluated. The same software package (MATs) as used for the PR was used to calculate the food and nutrient intake.

24-hours urine collection: Protein intake was validated by comparing the calculated intake with the 24-hour nitrogen excretion (8). Thirty-nine of 82 subjects collected a 24-hour urine sample during the WR period. That period was chosen since the WR was considered to be the reference method and also to limit the work-load for the subjects. PABA (para-amino-benzoic acid) tablets were used to check the completeness of the urine collection (9). Three PABA tablets containing $80 \mathrm{mg}$ each were taken during the 24-hour urine collection. One tablet was taken with each of the three main meals (breakfast, lunch, dinner). The urine collections containing less than $85 \%$ of the ingested PABA were considered incomplete. The urine collections were spread out over the week, so that each of the week-days would be represented at the same rate. Urine nitrogen excretion was converted to grams of protein ingested using the formula gram N/0.81 x 6.25, since it has been found that, on average, $81 \%$ of the nitrogen is excreted with the urine (9).

Participants' views of the PR: A questionnaire containing questions about the participants views of the two dietary record methods was sent to 25 of the participants after completion of the dietary study. The questionnaire contained questions about 
the time spent recording food intake, use of pictures in the PR, ease of recording food intake, etc. In addition, the time spent on coding and entering the data was estimated.

Statistics: Calculations were carried out with the SAS program (10) and included statistic procedures such as paired t-tests, Spearman's ranked correlations, and weighted Kappa $\left(\kappa_{\mathrm{w}}\right)$ analysis (11). $\kappa_{\mathrm{w}}>0.40$ indicates good agreement, and $\leq 0.40$ poor agreement.

\section{Results}

\section{Food intake}

The average daily intake of foods (aggregated into major food groups) obtained by the two methods is shown in Table 1. The intake of cheese and alcoholic drinks was higher $(p<0.05)$ and that of bread, breakfast cereals, vegetables, roots (excl. potatoes), lower $(\mathrm{p}<0.01)$ with the PR than with the WR. Otherwise, no statistical differences between the two methods were found. Also the relative differences between men and women were similar in the two methods (data not shown).

The correlation coefficients (Spearman) between the daily intake of the foods measured by the two methods ranged from 0.35 to 0.74 (Table 1). Kappa values, which reflects the agreement between the two methods with respect to classification of intakes into quintiles, were above 0.4 for foods like milk, cheese, bread and fruit, but below 0.4 for foods like spreads, potatoes, vegetables, meat and fish (Table 1).

Foodportions andfrequencies: Intake frequencies for most foods were relatively similar in the two methods (Table 2). Compared with the WR, the intake frequencies for spreads, milk, vegetables and sweet bakery products were lower $(\mathrm{p}<0.05)$ in the PR. To obtain a picture of differences between portion sizes recorded in the two methods, average portions of some foods were obtained by dividing the amounts consumed (for consumers only) by the intake frequencies. The results show that the average portions for milk, cheese, potatoes, juice, porridge, sweet bakery products, coffee and tea, were larger $(\mathrm{p}<0.01)$ and those of bread, breakfast cereals, pasta, vegetables, fruit, and meat dishes, smaller $(\mathrm{p}<0.05)$ in the PR than in the WR (Table 2).

Energy and nutrient intake: The average daily intakes of energy and nutrients as measured by the two methods are shown in Tables 3 and 4. The intake of energy and most nutrients did not differ significantly between the two methods. Significant differences were, however, seen for pro-
Table 3. Average daily intake of energy and nutrients, mean and (SD) measured by the record book $(P R)$ and the weighed record (WR) among adults $(n=82)$, Spearman correlation coefficients and Kappa values $\left(\kappa_{w}\right)$.

\begin{tabular}{|c|c|c|c|c|c|c|c|c|}
\hline \multirow[b]{2}{*}{ Energy } & \multirow[b]{2}{*}{ MJ } & \multicolumn{2}{|c|}{ PR } & \multicolumn{2}{|c|}{ WR } & \multirow[t]{2}{*}{$\mathrm{p}$} & \multirow{2}{*}{$\frac{\kappa_{\mathrm{w}}}{0.45}$} & \multirow{2}{*}{$\frac{\mathrm{r}}{0.62 * * *}$} \\
\hline & & 8.9 & $(2.0)$ & 9.0 & $(2.1)$ & & & \\
\hline Protein & $\mathrm{g}$ & 74 & (19) & 80 & (19) & $* *$ & 0.45 & $0.58 * * *$ \\
\hline Total fat & $\mathrm{g}$ & 88 & $(24)$ & 85 & $(23)$ & & 0.40 & $0.61 * * *$ \\
\hline Saturated fat & $\mathrm{g}$ & 37 & (11) & 36 & $(10)$ & & 0.46 & $0.66 * * *$ \\
\hline Monounsaturated fat & $\mathrm{g}$ & 31 & $(8.8)$ & 31 & $(8.6)$ & & 0.40 & $0.56 * * *$ \\
\hline Polyunsaturated & $\mathrm{g}$ & 13.4 & $(4.3)$ & 12.5 & $(3.8)$ & $*$ & 0.36 & $0.51 * * *$ \\
\hline Cholesterol & $\mathrm{g}$ & 0.32 & $(0.11)$ & 0.33 & $(0.11)$ & & 0.32 & $0.38 * * *$ \\
\hline Total carbohydrates & $\mathrm{g}$ & 242 & $(52)$ & 251 & (63) & & 0.42 & $0.63 * * *$ \\
\hline Monosaccharides & $\mathrm{g}$ & 29 & (12) & 33 & (15) & $* *$ & 0.32 & $0.44 * * *$ \\
\hline Sucrose & $\mathrm{g}$ & 43 & $(20)$ & 46 & $(21)$ & & 0.53 & $0.68 * * *$ \\
\hline Dietary fibre & $\mathrm{g}$ & 16.5 & $(4.0)$ & 18.3 & $(5.8)$ & $* * *$ & 0.48 & $0.59 * * *$ \\
\hline Alcohol & $\mathrm{g}$ & 9.7 & $(8.4)$ & 10.0 & $(10.1)$ & & 0.44 & $0.61 * * *$ \\
\hline \multicolumn{9}{|l|}{ Energy\% } \\
\hline Protein & & 14.3 & $(2.2)$ & 15.1 & $(2.0)$ & $* * *$ & 0.45 & $0.65 * * *$ \\
\hline Fat, total & & 36.2 & $(4.0)$ & 34.5 & $(4.1)$ & $* *$ & 0.23 & $0.38 * * *$ \\
\hline Saturated fat & & 15.5 & $(2.2)$ & 14.6 & $(2.2)$ & $* * *$ & 0.42 & $0.55 * * *$ \\
\hline Monounsaturated fat & & 12.6 & $(1.5)$ & 12.5 & $(1.8)$ & & 0.20 & $0.33 * *$ \\
\hline Polyunsaturated fat & & 5.5 & $(1.1)$ & 5.1 & $(0.9)$ & $* * *$ & 0.13 & $0.25 *$ \\
\hline Carbohydrates, total & & 46.6 & $(4.2)$ & 47.3 & $(5.1)$ & & 0.31 & $0.49 * * *$ \\
\hline Monosaccharides & & 5.6 & $(2.1)$ & 6.3 & $(2.3)$ & $* *$ & 0.39 & $0.58 * * *$ \\
\hline Sucrose & & 8.1 & $(3.3)$ & 8.6 & $(3.4)$ & & 0.49 & $0.62 * * *$ \\
\hline Alcohol & & 3.1 & $(2.7)$ & 3.0 & $(2.8)$ & & 0.43 & $0.59 * * *$ \\
\hline
\end{tabular}

The superscripts refer to level of significance, i.e. for difference in food intake and Spearman coefficients: $* \mathrm{p}<0.05 ; * * \mathrm{p}<0.01 ; * * * \mathrm{p}<0.001$ tein, monosaccharides, dietary fibre, $\beta$-carotene, $\alpha$-tocopherol, thiamin, preformed niacin, folate, iron, zinc (lower in PR) and polyunsaturated fatty acids (higher in PR).

The proportions of energy from protein and monosaccharides were significantly lower $(\mathrm{p}<0.01)$ for the PR than for the WR, while the proportions of energy from total fat, saturated and polyunsaturated fat were higher $(\mathrm{p}<0.01)$.

The correlation coefficients (Spearman) between the daily intake of energy and nutrients measured by the two methods were generally $0.5-0.7 \quad(p<0.001)$. For cholesterol, retinol and the proportion of energy from total fat, monounsaturated
Table 4. Average daily intake of micronutrients, mean and (SD) measured by the precoded record book $(P R)$ and the weighed record $(W R)$ among adults $(n=82)$, Spearman correlation coefficients and Kappa values $\left(\kappa_{w}\right)$.

\begin{tabular}{|c|c|c|c|c|c|c|c|c|}
\hline \multirow[b]{2}{*}{ Retinol } & \multirow[b]{2}{*}{$\mathrm{mg}$} & \multicolumn{2}{|c|}{ PR } & \multicolumn{2}{|c|}{ WR } & \multirow[t]{2}{*}{$\mathrm{p}$} & \multirow{2}{*}{$\frac{\kappa_{\mathrm{w}}}{0.22}$} & \multirow{2}{*}{$\frac{r}{0.26 *}$} \\
\hline & & 0.93 & $(0.63)$ & 0.84 & $(0.50)$ & & & \\
\hline$\beta$-carotene & $\mathrm{mg}$ & 1.93 & (1.32) & 2.41 & $(2.00)$ & $* *$ & 0.33 & $0.54 * * *$ \\
\hline Vitamin D & $\mu \mathrm{g}$ & 5.5 & (1.9) & 6.0 & $(3.0)$ & & 0.36 & $0.49 * * *$ \\
\hline$\alpha$-tocopherol & $\mathrm{mg}$ & 7.0 & $(2.2)$ & 7.9 & $(2.7)$ & $* *$ & 0.38 & $0.49 * * *$ \\
\hline Thiamin & $\mathrm{mg}$ & 1.36 & $(0.37)$ & 1.54 & $(0.41)$ & $* * *$ & 0.35 & $0.45 * * *$ \\
\hline Riboflavin & $\mathrm{mg}$ & 1.67 & $(0.47)$ & 1.68 & $(0.49)$ & & 0.48 & $0.59 * * *$ \\
\hline Niacin (pref.) & $\mathrm{mg}$ & 15.9 & $(3.5)$ & 18.0 & $(4.6)$ & $* * *$ & 0.41 & $0.54 * * *$ \\
\hline Vit $\mathrm{B}_{6}$ & $\mathrm{mg}$ & 1.94 & $(0.44)$ & 2.00 & $(0.48)$ & & 0.45 & $0.49 * * *$ \\
\hline Vit $B_{12}^{\circ}$ & $\mu \mathrm{g}$ & 6.2 & $(4.3)$ & 5.5 & $(3.6)$ & & 0.34 & $0.61 * * *$ \\
\hline Folate & $\mu \mathrm{g}$ & 206 & $(52)$ & 225 & $(55)$ & $* *$ & 0.28 & $0.43 * * *$ \\
\hline Vitamin C & $\mathrm{mg}$ & 74 & (34) & 79 & $(40)$ & & 0.44 & $0.41 * * *$ \\
\hline Calcium & $\mathrm{mg}$ & 1000 & (388) & 939 & (317) & & 0.46 & $0.67 * * *$ \\
\hline Potassium & $\mathrm{mg}$ & 3260 & $(625)$ & 3160 & (761) & & 0.34 & $0.62 * * *$ \\
\hline Sodium & $\mathrm{mg}$ & 3350 & $(884)$ & 3340 & $(1150)$ & & 0.28 & $0.52 * * *$ \\
\hline Magnesium & $\mathrm{mg}$ & 328 & (63) & 319 & $(75)$ & & 0.45 & $0.64 * * *$ \\
\hline Iron & $\mathrm{mg}$ & 14.3 & (3.3) & 16.4 & $(4.6)$ & $* * *$ & 0.39 & $0.56 * * *$ \\
\hline Zinc & $\mathrm{mg}$ & 10.3 & $(2.6)$ & 10.8 & $(2.7)$ & $*$ & 0.43 & $0.61 * * *$ \\
\hline Selenium & $\mu \mathrm{g}$ & 31 & $(9)$ & 32 & $(11)$ & & 0.34 & $0.43 * * *$ \\
\hline
\end{tabular}

The superscripts refer to level of significance, i.e. for difference in food intake and Spearman coefficients: ${ }^{*} \mathrm{p}<0.05 ; * * \mathrm{p}<0.01 ; * * * \mathrm{p}<0.001$ 
Table 5. Intake of protein measured by 24-h urinary nitrogen excretion (PABA recovery $>85 \%$ ) (UP), the precoded record book (PR) and the weighed record (WR). Men and women $(n=33)$, mean and (SD).

$U^{1} \quad$ PR $\quad$ WR

Protein intake (g/d) 91 (23) 73 (21) 81 (23)

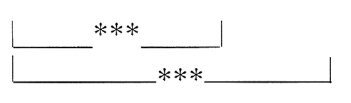

$* * * \mathrm{p}<0.001) ;{ }^{1}$ Collected

during the weighed record period.

Table 6. Participant attitudes to using the precoded record book (PR). Percent of answers $(n=25)$.

$\begin{array}{lr}\text { When filling in the PR, it was } & \\ \text { Very easy } & 8 \\ \text { Easy } & 68 \\ \text { Cumbersome } & 24 \\ \text { Very cumbersome } & 0 \\ \text { What did you think of having most } & \\ \text { foods preprinted, instead of doing } & \\ \text { the writing yourself? ( } n=23 \text { ) } & \\ \text { More easy } & 65 \\ \text { Less easy } & 4 \\ \text { No difference } & 22 \\ \text { Cannot say } & 9 \\ \text { When estimating portion sizes with } & \\ \text { the help of the pictures, it was (n=23) } & \\ \text { Very easy } & 57 \\ \text { Easy } & 26 \\ \text { Difficult } & 17 \\ \text { Very difficult } & 0 \\ \text { Did the precoding affect your eating? } & \\ \text { No } & 92 \\ \text { Yes, to some degree } & 8 \\ \text { How did the selection of foods in the } \\ \text { PR reflect your food choice? } \\ \text { Well } \\ \text { Relatively well } \\ \text { Less well } \\ \text { Not at all } \\ \end{array}$

Table 7. Comparison of average time $(\mathrm{min}) \mathrm{re}$ quired for data handling of the precoded record book (PR) and the weighed record (WR).

\begin{tabular}{lrr}
\hline & $\begin{array}{c}\text { WR } \\
\text { min }\end{array}$ & $\begin{array}{r}\text { PR } \\
\text { min }\end{array}$ \\
& & \\
\hline Coding & 90 & 20 \\
Entering data & 45 & 45 \\
Data checking & & \\
- nutrient calculation & 20 & 15 \\
Total time required & 155 & 80 \\
& & \\
\hline
\end{tabular}

and polyunsaturated fat correlation coefficients were $\leq 0.4(r=0.25-0.38$, Tables 3 and 4). Results of Kappa analysis indicated poor agreement $(\kappa=0,20-0,31)$ for the proportion of energy from total fat, mono- and polyunsaturated fat, and total carbohydrates (Table 3). Kappa values were close to or above 0.4 for most micro-nutrients. However, it was well below 0.4 for retinol, $\beta$-carotene, folate, vitamin $\mathrm{B}_{12}$, sodium and selenium (Table 4).

\section{Urinary nitrogen excretion}

The daily protein intake found with the PR was $20 \%$ lower $(\mathrm{p}<0.001)$, and the protein intake found with the WR $11 \%$ lower $(\mathrm{p}<0.001)$ than that calculated from the $24-\mathrm{h}$ urine (Table 5). The correlation coefficient between the urinary protein data and the intake found with the PR was 0.74 $(p<0.001)$ and $0.68(p<0.001)$ for the WR (men and women combined). If the six subjects for which PABA recovery was less than $85 \%$ are included, the results were not affected to any significant extent.

\section{Use of scale in the WR}

In the weighed 7-day food record, the men and women reported, on average, 43 and 47 eating events, respectively. Among those, the scale was used to weigh all the food items in $89 \%$ (men) and $92 \%$ (women) of the eating events. This corresponded to $89 \%$ and $92 \%$ of the total energy intake coming from weighed eating events among men and women, respectively. The remaining energy came from estimated amounts of food by use of pictures, drawings, etc. There were no significant differences in the proportion of energy intake from weighed and estimated eating events between men and women.

Of the different meal categories, the scale was used in more than $90 \%$ of the breakfast meals, dinners and other meals, while it was used in $70-80 \%$ of the lunch meals. There were no significant differences between men and women for any of the meal categories.

\section{Participants' views - precoded PR}

The participants were, in general, positive towards the PR and found it easy to use (Table 6). Of the 25 persons answering the questionnaire, 23 stated that they were not influenced by the fact that certain foods were precoded. Seven thought that the selection of food items reflected their food choice "well" and 18 "relatively well". Almost all (22 to 25 persons depending on meal type) thought that the meal structure coincided "well" or "relatively well" with their eating habits. Nineteen thought it was "very easy" or "easy" to estimate their portion sizes with help of the photographs.
The participants found it easier and less time-consuming to record their food intake with the PR than to weigh the foods. Typically, a person spent $10-15$ min per day filling in the PR and 20-30 min for the 7-day WR.

\section{Coding and entering of data}

In connection with the study, the time spent on coding and entering the data from the PRs and the WRs was estimated. The total times spent on these activities were ca. $150 \mathrm{~min}$ for a WR and ca. $80 \mathrm{~min}$ for a precoded PR, with most of the time saving in the coding step (Table 7).

\section{Discussion}

An analysis of the data indicated that the noted differences in food intakes in most cases were associated with the amounts eatenat each meal, rather than with intake frequencies. This might indicate that some of the standard portions used in the PR did not reflect actual portion sizes, e.g. for some types of bread (a slice of white bread and a piece of Swedish crisp bread), cheese (slices), milk (a glass) and certain types of foods that were to be estimated with the help of the photos, e.g. prepared vegetables, salads and pasta. For milk, some of the observed differences might have arisen due to the fact that use of "a glass" would tend to overestimate the amount of milk used for porridge. Also for some other foods, e.g. fruit and meats, average portions differed between the methods, but without resulting in significant differences in the average daily intakes.

The average intake of energy and most nutrients did not differ significantly between the two methods. However, the intake of protein and monosaccharides, dietary fibre, iron, $\beta$-carotene, $\alpha$-tocopherol, thiamin, folate and zinc was lower and the E\% from fat was higher with the PR than with the WR. The difference was generally within 5-10\%, except for carotene (ca. 20\% ). These differences could largely be attributed to the apparent overestimation of the intake of cheese and the apparent underestimation of the intakes of bread and cereals, meat dishes and vegetables.

A key question in this type of validation study is how much of any observed difference in dietary habits can be attributed to the methods and to differences in the true dietary intake during two periods. Few studies have compared food intake measured with a 7-day record method during separate weeks. In a comprehensive study, Adelson (12) compared food and nutrient intake of 39 well-educated American men recorded during two consecutive weeks. Food eaten at home was weighed and 
amounts of food eaten away from home were estimated in household measures. The average intake of major food groups varied within $10 \%$ between the first and second week. For sub-groups and individual items the variation was usually within $20 \%$. These figures are probably close to the best that one could expect with respect to week-to-week correlation of food intakes since records were kept during two consecutive weeks and the mean energy and nutrient intakes were very similar (within 5\%) between the two weeks. In the present study, the mean differences in average intake of foods (aggregated into food groups) between the WR and PR methods were within $10 \%$ or $20 \%$ for most foods, which is somewhat higher that the figures reported by Adelson (12).

Few studies have reported the intraindividual correlation of energy and nutrient intakes measured with a 7-day record method during two separate weeks (1316). The ranked correlation coefficients in this study $(0.5-0.7)$ are of an order that could be expected when food intakes during two separate weeks are compared and similar to those reported by Bingham et al. (13) between a 16-day weighed and a 7day estimated record (0.5-0.8).

The weighed record has generally been regarded as one of the most reliable methods of measuring an individual's dietary intake $(18,19)$, although the extensive work for the subject might affect compliance. Therefore, this method was chosen as the reference method in this study. The participants were instructed to weigh carefully all foods they consumed. The participants also received a portion guide with photos and drawings of portions to be used in situations where it would be inappropriate

\section{References}

1. Becker W: Befolkningens kostvanor och näringsintag i Sverige 1989. Metod- och resultatanalys. Food habits and nutrient intake in Sweden 1989. (In Swedish with English summary). Statens Livsmedelsverk, Uppsala 1994.

2. Becker W, Johansson G: Menybokföring som komplement till hushållsbok (Food record by menu as a complement to a household diary) Vår Föda 1987:39 (suppl. 1):95-102.

3. Becker W: Kostvanorna i södra Sverige resultat från en provundersökning (Food habits in southern Sweden - results from a pilot survey) Vår Föda 1990;42:322-33.

4. Nydahl M, Gustafsson I-B, Mohsen R, Vessby $\mathrm{B}$ : The nutrient and food intake of Swedish nonsmokers and smokers. Scand J Nutrition/ Näringsforskning 1996:40:64-9.

5. Vikttabeller för livsmedel och maträtter. Statens livsmedelsverk, Uppsala: 1992

6. PC-Kost 94. Statens Livsmedelsverk 1994

7. Nordin M: MATs. Nutrient calculation system designed for research and education, Rudans Lättdata, Västerås, 1994

8. Isaksson B: Urinary nitrogen output as a validity test in dietary surveys. Am J Clin Nutr 1980;33:4-6.

9. Bingham SA, Cummings $\mathbf{J H}$ : Urine nitrogen as an independent validatory measure of dietary intake: a study of nitrogen balance in indivi- to use the scale. Our results show that the scale was used in the majority of eating events. Estimation of portion sizes was only done for ca. $10 \%$ of the eating events, and about $10 \%$ of the total energy intake came from these eating events.

Recent developments in measurement of energy expenditure, i.e. the use of doubly labelled water, has, however, shown that underestimation of food intake by adults and adolescents is a general problem with record methods $(19,20)$. The energy intakes in this study are comparable to those in other large dietary surveys in which 7day records have been used $(1,4,21)$. The average PAL-values were 1.3-1.4, with no differences between the two methods, indicating a substantial underestimation of the habitual energy intake. In our study, the protein intake was validated using $24-h$ urinary collections in a sub-sample of subjects. The results show that the dietary protein intake was $11 \%$ lower with the WR and $20 \%$ lower with the PR compared with the protein intake estimated from urinary nitrogen data for the WR period, thus indicating a significant underestimation of the food intake for both methods. Correlation coefficients (Spearman) between protein intake calculated from urinary protein and dietary protein were 0.68 for the WR and 0.74 for the PR, respectively, which are similar to those obtained by Bingham et al. (18) for weighed (0.78-0.87) and estimated records (0.600.70 ) with eight 24 -h urines per subject. The correlation coefficients from the present study were somewhat higher than expected, a priori, as only one 24-h urine was collected from each subject.

Most of the participants found it easier and less time-consuming to fill in the PR than to weigh their foods. The PR was included in an extensive household budget survey and thus it was important to limit the workload of the participants.

An important advantage of precoded record books, compared with open-ended records, is that considerable time may be saved in coding and entering of data. In the present study, the time reduction was almost $50 \%$, so that coding and entering of data from the PR took 1.3 hours per person instead of 2.5 hours for the WR. In a study including 500 participants, this time saving would mean a saving of 4 months' work. As precoded record books can easily be worked out in a form suitable for optical scanning, even more time could be saved in this way, thus avoiding the timeconsuming step of entering the data manually (22).

The overall result of this comparative study is that the PR method gave a reasonably similar picture of the average food and nutrient intake in the studied group of adults, as compared to the WR method. However, both methods underestimated the energy and protein intake. The results also indicate that some of the standard portion sizes used in the PR could have contributed to the apparent over- or underestimation of the intake of certain foods, e.g cheese, bread and vegetables. The results of the study will be used for improvements in the design of the PR for use in large-scale dietary surveys for monitoring dietary habits.

\section{Acknowledgements}

Lars Berglund, Dept of Medical Sciences, Uppsala, is acknowledged for assistance with statistical analyses and Maria Munoz, National Food Administration, for coding and processing the dietary data.The work was supported by the National Food Administration and the National Institute of Public Health duals consuming their normal diet. Am J Clin Nutr 1985;42:1276-89.

10. SAS Institute Inc.: SAS user's guide. Cary, NC: SAS 1982.

11. Fleiss JL: Statistical methods for rates and proportions. Second edition. John Wiley \& Sons New York: 1981

12. Adelson SF: Some problems in collecting dietary data from individuals. J Am Diet Assoc 1960;36:453-61.

13. Bingham SA, Gill C, Welch A, Day K, Cassidy A Khaw KT, Sneyd MJ, Key TJA, Roe L, Day NE: Comparison of dietary assessment methods in nutritional epidemiology: weighed records v. 24$\mathrm{h}$ recalls, food-frequency questionnaires and estimated-diet records. Br J Nutr 1994; 72:619-43.

14. Block G: A review of validations of dietary assessment methods. Am J Epidemiol 1982 115:492-505

15. Marr JW: Individual dietary surveys: Purposes and methods. World Rev Nutr Diet 1971; 13:105-64.

16. Jørgensen LM, Isaksson B, Schroll M: Reproducibility and validity of 7-day food records Eur J Clin Nutr 1992;46:729-34.

17. Bingham S: The dietary assessment of individuals; methods, accuracy, new techniques and recommendations: Nutr Abstr Rev 1987; $57: 705-42$
18. Bingham SA, Cassidy A, Cole TM, Welch A Runswick, SA, Black AE, Thurnham D, Bates C, Khaw KT, Key TJA, Day NE: Validation of weighed records and other methods of dietary assessment using the 24-h urine nitrogen technique and other biological markers. Br J Nutr 1995; 73:531-50

19. Black AE Goldberg GR Jebb SA Livingstone MBE, Cole TJ, Prentice AM: Critical evaluation of energy intake using fundamental principles of energy physiology: 2. Evaluating the results of published surveys. Eur J Clin Nutr 1991;45 583-99.

20. Bratteby L-E, Sandhagen B, Fan H, Samuel son $\mathrm{G}$ : Total energy expenditure and physical activity as assessed by the doubly labeled water method in Swedish adolescents in whom energy intake was underestimated by 7-d diet records. Am J Clin Nutr 1998;67: 905-11.

21. Gregory J, Foster K, Tyler H, Wiseman M: The dietary and nutritional survey of British adults. Office of Population Censuses and Surveys. Social Survey Division. London: HMSO 1990

22. Haraldsdottir J, Gustafsson I-B, Becker W: Pre coded food records: An alternative to food frequency questionnaires in epidemiological surveys? Abstract. 7th European Nutrition Conference, Vienna, May 24-28, 1995 